\title{
Efficacy of semiochemical-baited traps for detection of longhorn beetles (Coleoptera: Cerambycidae) in the Russian Far East
}

\author{
Jon D. SWEENEY ${ }^{1}$, Peter J. SILK ${ }^{1}$ and VASILY GREBENNIKOV ${ }^{2}$ \\ ${ }^{1}$ Natural Resources Canada, Canadian Forest Service - Atlantic Forestry Centre, 1350 Regent Street, PO Box 4000, Fredericton, NB, \\ E3B5P7, Canada; e-mails: jon.sweeney@nrcan.gc.ca; psilk@nrcan.gc.ca \\ ${ }^{2}$ Ottawa Plant Laboratory, Canadian Food Inspection Agency, 960 Carling Ave, K.W. Neatby Building, Ottawa, ON K1A 0C6, \\ Canada; e-mail: vasily.grebennikov@inspection.gc.ca
}

Key words. Coleoptera, Cerambycidae, longhorn beetles, semiochemical, traps, detection, Russian Far East

\begin{abstract}
The efficacy of various combinations of pheromones and plant volatile lures for detection of longhorn beetles (Coleoptera: Cerambycidae) in traps was tested in field bioassays in a mixed coniferous-deciduous forest near Vladivostok in the Russian Far East in 2009 and 2010. Traps detected 30 species (490 specimens) in 2009 and 23 species (182 specimens) in 2010. Overall, 38 longhorn beetle species were detected, with 15 species common to both years. Species composition differed among lure treatments, but the number of species detected with any single lure did not vary significantly among lures (12-16 species per lure in 2009; 3-10 species per lure in 2010). Type of lure significantly affected mean catch per trap of five species in 2009 and 2010. For these same species, lure type also significantly affected the efficacy of detection, i.e., the proportion of traps that captured at least one specimen of a given species. The combination of racemic $E$-fuscumol and spruce blend (a blend of five monoterpenes) positively affected mean catch of Tetropium castaneum (L.). Racemic 3-hydroxyhexan-2-one (K6), alone or combined with ethanol, increased mean catch of Anaglyptus colobotheoides Bates. The combination of K6 and ethanol increased mean catch of Phymatodes testaceus (L.), and the combination of racemic 3-hydroxyoctan-2-one and ethanol increased mean catch of Molorchus minor (L.). Use of longhorn beetle pheromone lures in trapping surveys increases the mean catch and probability of detecting certain species of Cerambycidae, including those that may be exotic and potentially invasive. Sample-based rarefaction indicated that eight traps per site were insufficient to detect all of the longhorn species potentially attracted by any individual lure treatment, i.e., species accumulation curves failed to reach an asymptote in most cases.
\end{abstract}

\section{INTRODUCTION}

Invasive wood-boring beetles such as the Asian longhorned beetle, Anoplophora glabripennis Motschulsky, and the emerald ash borer, Agrilus planipennis Fairmaire, have killed millions of trees and cost millions of dollars in efforts to eradicate or control their spread in North America (Nowak et al., 2001; Poland \& McCullough, 2006; Kovacs et al., 2010). These invasive species have often been detected by chance by a member of the general public several years after the estimated year of establishment (Cappaert et al., 2005). Recent implementation of International Standards on Phytosanitary Measures (ISPM) 15 (FAO IPPC, 2013), which requires the phytosanitary treatment and certification of wood packaging material, will reduce but not eliminate new introductions of exotic wood-boring beetles. Improved survey tools for effective early detection of invasive forest insects are therefore critically needed.

In recent years, sex and aggregation pheromones have been identified in several species of longhorn beetles in the subfamilies Cerambycinae (Fettköther et al., 1995; Leal et al., 1995; Allison et al., 2004; Lacey et al., 2004, 2007), Spondylidinae (Silk et al., 2007; Sweeney et al., 2010), Prioninae (Cervantes et al., 2006), Lamiinae (Zhang et al., 2002; Nehme et al., 2009; Fonseca et al., 2010, Pajares et al., 2010; Teale et al., 2011), and Lepturinae (Ray et al., 2011). In the Cerambycinae, the pheromones are usually 6-, 8- or 10-carbon 2,3-ketols or diols with specific chiral- ity and are emitted by males from pores on the prothorax (Ray et al., 2006). In contrast to the Lepidoptera, in which attraction of a particular moth species to a synthetic lure is highly dependent on the relative ratio and chirality of pheromone components (Roelofs \& Cardé, 1977), longhorn beetle pheromones often attract several species in the same genus or subfamily and thus have good potential as survey tools of native and exotic Cerambycids (Millar et al., 2009; Hanks \& Millar, 2012). Hanks et al. (2007) found that individual species of Cerambycinae usually emitted specific enantiomers, e.g., $(R)$-3-hydroxyhexan-2-one, but the presence of other enantiomers in synthetic lures did not reduce attraction; they hypothesized that the 2,3-diol/hydroxyketone pheromone motif was highly conserved within the subfamily and predicted that multiple Cerambycinae species would be attracted to compounds of this type. Similarly, (E)-6,10-dimethyl-5,9-undecadien-2-ol (fuscumol), the aggregation pheromone of Tetropium fuscum (Fabr.) and T. cinnamopterum (Kirby) (Silk et al., 2007), is also attractive to T. castaneum (L.) (Sweeney et al., 2010) and three species of Lamiinae (Mitchell et al., 2011).

Attraction of longhorn beetles to their pheromones is frequently synergized by the addition of host plant volatiles (Sweeney et al., 2010; Hanks \& Millar, 2012). For example, ethanol is emitted from stressed trees (Kimmerer \& Kozlowski, 1982) and synergizes attraction of T. fuscum (Sweeney et al., 2004, 2006) as well as bark beetles (Tilles et al., 1986) to terpenes. We hypothesized that the com- 
bination of ethanol and racemic ketols would synergize attraction of longhorn beetles and thus increase detection efficacy. Ethanol is commonly used as a general host attractant in annual trapping surveys to detect the presence of exotic bark- and wood-boring beetles in North America, so data on its efficacy for detecting longhorn species native to Europe and Asia would be highly useful. Finally, we also wanted to determine whether adding ketol lures to traps baited with ethanol would reduce the catch of species attracted to ethanol by itself. If several lures can be placed on a single trap without a net loss in the number of species detected, survey efficiency would be increased (Hanks et al., 2012; Wong et al., 2012).

Our goal is to develop improved tools for survey and early detection of non-native, potentially invasive bark- and wood-boring insects that have been inadvertently moved between continents in solid wood packaging material. The objectives of this study were (1) to determine the efficacy of synthetic pheromone and plant volatile lures for detecting longhorn beetles species in traps in the Russian Far East; and (2) to test the effect of ethanol on the efficacy of pheromones for longhorn beetle detection.

\section{MATERIAL AND METHODS}

We conducted two field trapping bioassays in the Russian Far East, one from 30 May-8 August 2009 and the other from 23 May-21 July 2010, to compare a total of eight different semiochemical lure treatments for their efficacy in detecting species of longhorn beetles. Unbaited traps were included as controls in both years.

\section{Trapping site}

Both experiments were run on the same site in a relatively undisturbed mixed broadleaf-coniferous forest next to the properties of S.R. Shestakov, some $5 \mathrm{~km}$ south of the village Anisimovka in Shkotovsky rayon, Primorsky Kray, Russia $\left(43.1268^{\circ} \mathrm{N}\right.$, $132.7973^{\circ} \mathrm{E} ; 450 \mathrm{~m}$; Fig. 1). This area near Vladivostok in the Russian Far East has similar climate and shares many genera of trees and longhorn beetles with parts of northeastern China (Manchuria) (Krestov, 2003) as well as northeastern North America and was therefore highly suitable for testing the efficacy of lures for detecting species of longhorned beetles with potential for inadvertent introduction and possible establishment in Canada.

\section{Semiochemicals, lures, and release rates}

Racemic (E)-fuscumol ( $>99 \%$ pure; GC/MS), hereafter referred to as "F", was synthesized at the Atlantic Forestry Centre (AFC) by lithium aluminum hydride reduction of commercially available $(E)$-geranyl acetone (Aldrich Chemicals, Milwaukee, WI, USA; $<0.5 \%$ Z-isomer), and the structure of the secondary alcohol verified by Electrospray Ionization mass spectrum, and $1 \mathrm{H}$ and $13 \mathrm{C}$ Nuclear Magnetic Resonance (Silk et al., 2007). Racemic $(E)$ fuscumol acetate, hereafter referred to as "FA", was synthesized by treating fuscumol with acetic anhydride/pyridine/dimethyl aminopyridine. Release devices for $\mathrm{F}$ and FA were $0.2 \mathrm{ml}$ thin-wall, clear, dome-capped polymerase chain reaction (PCR) sample tubes (Axygen Scientific Inc., Union City, CA, USA) containing ca. $15 \mathrm{mg}$ of synthetic pheromone, with a $1 \mathrm{~mm}$ diam. hole drilled in the cap. Release rate of $\mathrm{F}$ was initially 800 $\mu \mathrm{g} / \mathrm{d}$, dropping to about $80 \mu \mathrm{g} / \mathrm{d}$ after $30 \mathrm{~d}$ at $23^{\circ} \mathrm{C}$ (determined by weight loss). The release rate of FA was not determined but assumed to be greater than that of fuscumol due to greater volatil- ity. For traps baited with F or FA, we placed one lure per trap and replaced the lures after 4 weeks.

Racemic 3-hydroxyhexan-2-one, hereafter referred to as "K6" (i.e., 6 carbon ketol) and racemic 3-hydroxyoctan-2-one, hereafter referred to as "K8", were purchased commercially (Bedoukian Research Inc., Danbury, CT), verified as $99 \%$ pure by GC/MS at $\mathrm{AFC}$, and loaded into release devices at Contech Inc. (Delta, $\mathrm{BC}$ ). The release devices consisted of a piece of cellulose sponge $(7.0 \mathrm{~cm} \times 5.0 \mathrm{~cm} \times 0.5 \mathrm{~cm})$ inside a polyethylene pouch into which $1.4 \mathrm{~g}$ of either $\mathrm{K} 6$ or $\mathrm{K} 8$ was pipetted, and the pouch heatsealed. The release rates, determined gravimetrically at $20^{\circ} \mathrm{C}$, were $20 \mathrm{mg} / \mathrm{d}$ and $25 \mathrm{mg} / \mathrm{d}$ for K8 and K6, respectively. For traps baited with either $\mathrm{K} 6$ or K8, we placed two pouches per trap to obtain release rates of $40-50 \mathrm{mg} / \mathrm{d}$ and did not replace the lures. Unlike some earlier studies (e.g., Hanks et al., 2007), in which the diols/hydroxyketones were formulated in ethanol, our hydroxyketone lures did not use ethanol as a carrier, which allowed us to independently test whether the presence of ethanol increased or decreased attraction to the hydroxyketone lures, and vice versa.

Ultra high release rate lures of spruce blend (also known as brown spruce longhorn beetle kairomone, hereafter referred to as "SB") and ethanol, hereafter referred to as "E", were purchased commercially (Contech Inc, Delta, BC). Release rates of SB (44\% racemic $\alpha$-pinene, 19\% (-) $\beta$-pinene, 10\% (+)-3-Carene, $18 \%(+)$-limonene, and $9 \% \alpha$-terpinolene) and $\mathrm{E}$ lures were about 2,000 mg/d and $275 \mathrm{mg} / \mathrm{d}$, respectively (Sweeney et al., 2006). Due to difficulties in shipping and receiving ethanol lures (considered dangerous goods) to Russia in 2010, we purchased empty ethanol release devices from Contech Inc. and filled them with locally purchased Vodka ( $40 \%$ ethanol), sealing the top of the release device by folding the top of the sleeve over twice and pinching it with a strong paper clamp. This likely reduced the release rates of ethanol in 2010 to about half of that in 2009. For traps baited with $\mathrm{E}$ or SB, we placed one lure per trap and did not replace the lures (Fig. 1).

\section{Experimental design}

Experiments were replicated in randomized complete block designs with eight replicates per treatment and 20-30 m spacing between traps and blocks. Black panel intercept traps (Alpha Scents, Inc., Portland OR) (Fig. 1) were suspended from rope tied between two trees so that the collecting cup was at least $30-60 \mathrm{~cm}$ above the ground and the trap was at least $1 \mathrm{~m}$ distant from each tree (Fig. 1). Collecting cups were partially filled with commercially available car cooling fluid consisting of approximately $60 \%$ ethylene glycol and $40 \%$ water. Traps were emptied every week for a total of 8-10 weeks, and captured insects sealed in Whirlpak bags with $96 \%$ ethanol labeled by date, lure treatment, and block, and stored at room temperature until sorting was completed.

\section{Specimen identification, deposit, and taxonomy}

All longhorn beetle specimens were identified to species, with one exception: the morphologically similar Asemum striatum (L.) and A. punctulatum Bless. were not confidently separated and, therefore, grouped as one composite Asemum spp. Pinned voucher specimens were deposited in the Canadian National Collection of Insects, Arachnids and Nematodes in Ottawa. Species' names and classification were adopted following Löbl \& Smetana (2010).

\section{Data analysis}

For each longhorn species, numbers of specimens captured per trap were summed over the entire $8-10$ week trapping period for each experiment. A chi-square goodness-of-fit test was used to test whether the number of longhorn beetle species detected differed among lure treatments. For species for which a total of 


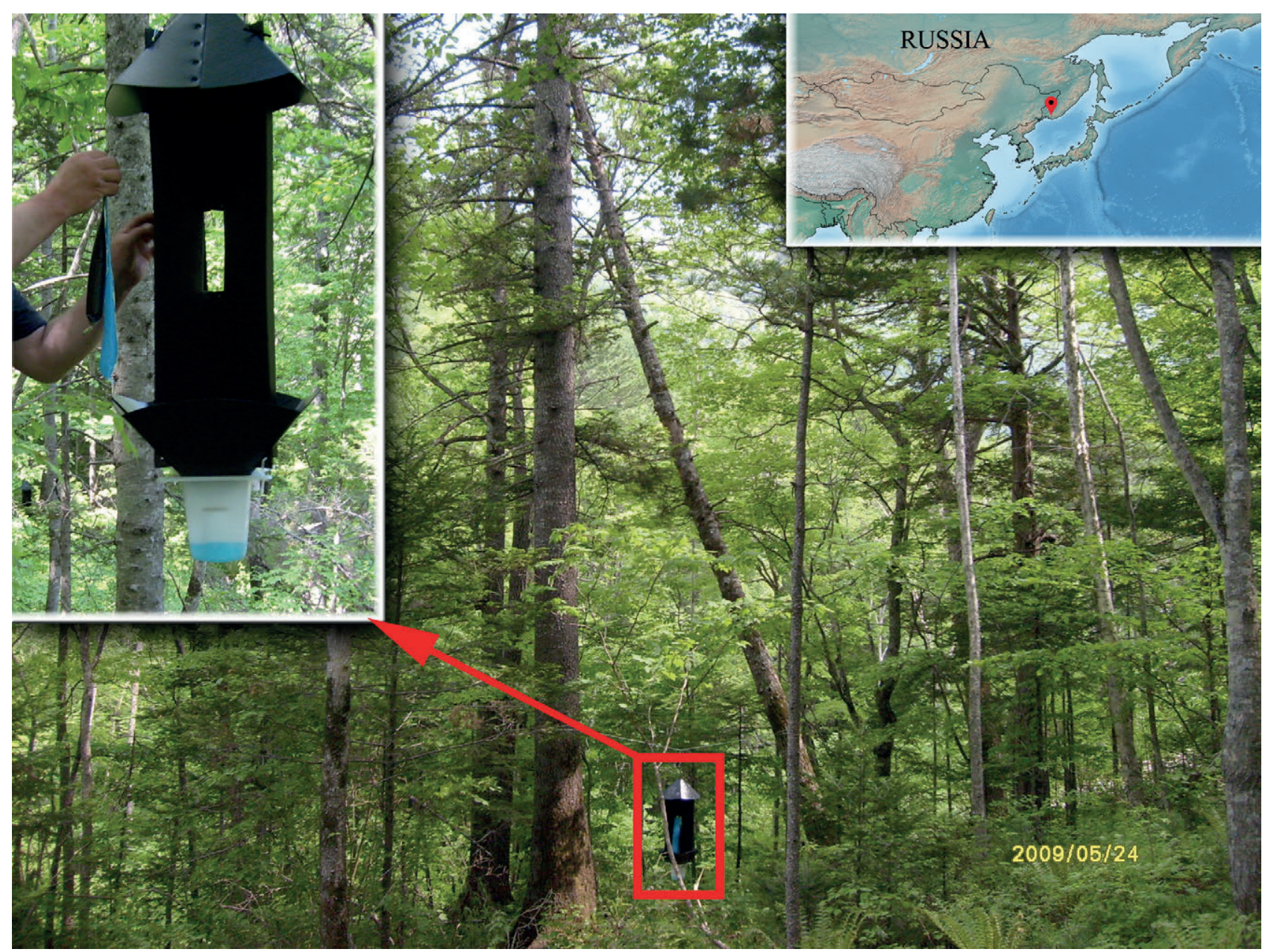

Fig. 1. Lures, trap, and the trapping site in the Russian Far East.

three or more specimens were captured, Cochran's $Q$ test for dichotomous data in randomized blocks (Zar, 1999) was used to test the null hypothesis that the proportion of traps that collected at least one specimen of that species was the same for all lure treatments $(\alpha=0.05)$, i.e., a significant $Q$ value indicated that lure treatments differed in efficacy of detecting a given species. For species for which at least ten specimens were captured, data on the number of specimens per trap were first transformed by $\log (\mathrm{y}+1)$ and then subjected to ANOVA using the model: catch = block + lure treatment + error, using SAS PROC GLM (SAS Institute, 2002-2003). Residuals were checked for normality using Shapiro-Wilks test in SAS PROC Univariate. If residuals of the log-transformed data departed significantly from normality, the raw values were rank transformed and subjected to GLM (Friedman's Test, Zar, 1999). For both log- and rank-transformed data, means were compared using the Ryan-Einot-Gabriel-Welsh multiple comparison test in SAS GLM.

The degree of similarity in species composition among lure treatments was determined by calculating the qualitative Sorensen index, which compares incidence of species, and the quantitative Morasita-Horn index (MH), which compares both incidence and abundance of species; both indices were calculated using EstimateS version 9 (Colwell, 2013). EstimateS was also used to calculate the mean number of species detected per number of trap samples using Coleman's rarefaction. This was done to compare the number of species detected versus trapping effort among individual lure treatments as well as combinations of two to three lure treatments. Coleman's rarefaction does not estimate true species richness but only the average number of species detected per
$1,2 \ldots n$ samples (i.e., trap samples in our case) collected from a given area. In this sense, it provides a measure of how many traps are needed to detect most of the species liable to be detected with a given lure treatment, or conversely, the proportion of species that may go undetected when the number of traps per site is limited.

\section{RESULTS}

Traps detected 30 longhorn beetle species (490 specimens) in 2009 (Table 1) and 23 species (182 specimens) in 2010 (Table 2). Overall, 38 longhorn species were detected, with 15 species common to both years. The number of specimens detected varied significantly among lure treatments in both years, but the number of species detected did not (Tables 1, 2).

Lure treatment significantly affected mean catch per trap of five longhorn species in each year. The combination of F and SB significantly increased mean catch of Tetropium castaneum (L.) (Spondylidinae) $\left(F_{4,28}=6.8 ; P\right.$ $<0.0001$ ) (Fig. 2a). SB significantly increased mean catch of Asemum spp. $\left(F_{4,28}=14.2 ; P<0.0001\right)$ (Fig. 2b) and Pachyta bicuneata Motschulsky (Lepturinae) $\left(F_{4,28}=2.3\right.$; $P=0.04)$. Mean catch per trap of Anaglyptus colobotheoides Bates (Cerambycinae) differed significantly among lure treatments in both $2009\left(F_{4,28}=29.1 ; P<0.0001\right)$ and $2010\left(F_{5,35}=25.1, P<0.0001\right)$, with greatest catch in 
TABLE 1. Number of specimens of longhorn beetles (Cerambycidae) collected in 2009 near Vladivostok, Russia, in traps baited with different semiochemical lures (K6 = racemic 3-hydroxyhexan-2-one; $\mathrm{E}=$ ethanol; $\mathrm{SB}=$ spruce blend; $\mathrm{F}=$ racemic fuscumol; and $\mathrm{FA}$ = fuscumol acetate; $\mathrm{C}=$ unbaited control), eight replicates per treatment. Trinomina are given only for non-nominative subspecies. Bold font indicates species for which the proportion of traps that contained that species differed significantly among lure treatments (Cochran's Q test, Zar, 1999) and those lure(s) that had the greatest rate of detection; analysis was run only with species with total catch of three or more specimens. Total number of species detected overall or within subfamily did not differ among lure treatments $\left(\chi^{2}\right.$ goodness-of-fit test, $\left.P>0.05\right)$.

\begin{tabular}{|c|c|c|c|c|c|c|c|c|}
\hline $\begin{array}{l}\text { Subfamily } \\
\text { Tribe } \\
\text { Species }\end{array}$ & $\mathrm{K} 6+\mathrm{E}$ & $\mathrm{F}+\mathrm{SB}+\mathrm{E}$ & $A+S B+E$ & $\mathrm{SB}+\mathrm{E}$ & $\mathrm{C}$ & Total & Q & $P$ \\
\hline \multicolumn{9}{|l|}{ Cerambycinae } \\
\hline $\begin{array}{l}\text { Anaglyptini } \\
\text { Anaglyptus colobotheoides Bates }\end{array}$ & 17 & 0 & 0 & 0 & 1 & 18 & 28.7 & $<0.01$ \\
\hline Callidiini & & & & & & & & \\
\hline $\begin{array}{l}\text { Phymatodes testaceus (L.) } \\
\text { Clytini }\end{array}$ & 7 & 0 & 0 & 0 & 1 & 8 & 13.3 & 0.01 \\
\hline Rhaphuma gracilipes Matsumura & 3 & 1 & 0 & 1 & 1 & 6 & 4.8 & NS \\
\hline Xylotrechus ibex Gebler & 1 & 0 & 0 & 0 & 0 & 1 & - & - \\
\hline Molorchini & & & & & & & & \\
\hline \multirow{2}{*}{\multicolumn{9}{|c|}{ Lamiinae }} \\
\hline & & & & & & & & \\
\hline \multicolumn{9}{|l|}{ Acanthocinini } \\
\hline Leiopus albivittis Kraatz & 1 & 0 & 0 & 0 & 0 & 1 & - & - \\
\hline Leiopus stillatus (Bates) & 0 & 0 & 0 & 2 & 0 & 2 & - & - \\
\hline \multicolumn{9}{|l|}{ Mesosini } \\
\hline Mesosa myops (Dalman) & 0 & 0 & 0 & 0 & 1 & 1 & - & - \\
\hline Monochamus saltuarius (Gebler) & 0 & 1 & 0 & 1 & 0 & 2 & - & - \\
\hline Monochamus urussovii Fisch. & 0 & 3 & 3 & 3 & 0 & 9 & 7.1 & NS \\
\hline \multicolumn{9}{|l|}{ Saperdini } \\
\hline $\begin{array}{l}\text { Eutetrapha sedecimpunctata Motsch. } \\
\text { Lepturinae }\end{array}$ & 1 & 0 & 0 & 0 & 0 & 1 & - & - \\
\hline \multicolumn{9}{|l|}{ Lepturini } \\
\hline Anastrangalia sequensi (Reitter) & 0 & 0 & 1 & 1 & 0 & 2 & - & - \\
\hline Grammoptera cyanea Tamanuki & 0 & 0 & 1 & 0 & 0 & 1 & - & - \\
\hline Leptura annularis Fabricius & 0 & 0 & 0 & 0 & 1 & 1 & - & - \\
\hline Stictoleptura variicornis (Dalman) & 0 & 1 & 0 & 1 & 0 & 2 & - & - \\
\hline Xestoleptura baeckmanni (Plav.) & 0 & 1 & 0 & 0 & 0 & 1 & - & - \\
\hline \multicolumn{9}{|l|}{ Rhagiini } \\
\hline Acmaeops septentrionis Aurivillius & 0 & 0 & 1 & 1 & 1 & 3 & 2.4 & NS \\
\hline Brachyta sachalinensis Matsumura & 0 & 1 & 0 & 0 & 1 & 2 & - & - \\
\hline Evodinus borealis (Gyllenhal) & 0 & 0 & 1 & 1 & 0 & 2 & - & - \\
\hline Gaurotes virgínea kozhevnikovi Plav. & 0 & 1 & 1 & 0 & 0 & 2 & - & - \\
\hline Pachyta bicuneata Motsch. & 0 & 7 & 9 & 10 & 0 & 26 & 14.7 & $<0.01$ \\
\hline Pidonia puziloi (Solsky) & 0 & 1 & 1 & 0 & 0 & 2 & - & - \\
\hline Pidonia alticollis (Kraatz) & 1 & 0 & 1 & 1 & 1 & 4 & 1.0 & NS \\
\hline Pidonia similis Kraatz & 0 & 0 & 0 & 1 & 1 & 2 & - & - \\
\hline Rhagium inquisitor rugipenne Reitter & 1 & 2 & 1 & 1 & 6 & 11 & 2.7 & NS \\
\hline \multicolumn{9}{|l|}{ Sachalinobiini } \\
\hline Sachalinobia koltzei (Heyden) & 2 & 0 & 1 & 0 & 5 & 8 & 5.7 & NS \\
\hline \multicolumn{9}{|l|}{ Necydalinae } \\
\hline \multicolumn{9}{|l|}{ Necydalini } \\
\hline Necydalis pennata Lewis & 4 & 0 & 0 & 0 & 1 & 5 & 5.3 & NS \\
\hline Necydalis sachalinensis Matsumura \& Tamanuki & 0 & 1 & 4 & 1 & 1 & 7 & 4.4 & NS \\
\hline \multicolumn{9}{|l|}{ Spondylidinae } \\
\hline \multicolumn{9}{|l|}{ Asemini } \\
\hline Asemum spp. Eschscholtz & 0 & 87 & 70 & 88 & 7 & 252 & 29.6 & $<0.01$ \\
\hline Tetropium castaneum (L.) & 1 & 76 & 10 & 15 & 3 & 105 & 14.6 & $<0.01$ \\
\hline No. species detected & 12 & 13 & 16 & 14 & 14 & 30 & $3.1^{1}$ & NS \\
\hline No. specimens captured & 42 & 183 & 107 & 127 & 31 & 490 & $161^{1}$ & $<0.001$ \\
\hline
\end{tabular}

${ }^{1}$ Chi-square goodness-of-fit test, where null hypothesis is equal frequency of species or specimens among lure treatments.

traps baited with either K6 or K6+E (Figs 2c, d). Similarly, the combination of $\mathrm{K} 6+\mathrm{E}$ significantly increased catch of Phymatodes testaceus (L.) (Cerambycinae) in 2009 ( $F_{4,28}$
$=5.2 ; P=0.003)$ and $2010\left(F_{5,35}=6.6, P=0.0002\right)$. Traps baited with the combination of $\mathrm{K} 8+\mathrm{E}$ had greatest mean catches of Molorchus minor (L.) (Cerambycinae) $\left(F_{5,35}=\right.$ 
TABLE 2. Number of specimens of longhorn beetles (Cerambycidae) collected in 2010 near Vladivostok, Russia, in traps baited with different semiochemical lures ( $\mathrm{E}=$ ethanol; K6 = racemic 3-hydroxyhexan-2-one; K8 = racemic 3-hydroxyoctan-2-one, $\mathrm{C}=$ unbaited control), and eight replicates per treatment. Trinomina are given only for non-nominative subspecies. Bold font indicates species for which the proportion of traps that contained that species differed significantly among lure treatments (Cochran's Q test, Zar, 1999) and the lure(s) that had the greatest rate of detection; analysis was run only with species with total catch of three or more specimens. Total number of species detected overall or within subfamily did not differ among lure treatments ( $\chi^{2}$ goodness-of-fit test, $P>0.05$ ).

\begin{tabular}{|c|c|c|c|c|c|c|c|c|c|}
\hline $\begin{array}{l}\text { Subfamily } \\
\text { Tribe } \\
\text { Species }\end{array}$ & $\mathrm{E}$ & $\mathrm{K} 6+\mathrm{E}$ & $\mathrm{K} 8+\mathrm{E}$ & K6 & K8 & $\mathrm{C}$ & Total & Q & $\mathrm{P}$ \\
\hline \multicolumn{10}{|l|}{ Cerambycinae } \\
\hline \multicolumn{10}{|l|}{ Anaglyptini } \\
\hline Anaglyptus colobotheoides Bates & 0 & 33 & 4 & 39 & 0 & 0 & 76 & 31.3 & $<0.01$ \\
\hline \multicolumn{10}{|l|}{ Callidiini } \\
\hline Phymatodes testaceus (L.) & 1 & 13 & 0 & 4 & 0 & 0 & 17 & 18.1 & $<0.01$ \\
\hline Poecilium maacki Kraatz & 1 & 0 & 0 & 0 & 0 & 0 & 1 & - & - \\
\hline \multicolumn{10}{|l|}{ Clytini } \\
\hline Rhaphuma gracilipes Matsumura & 4 & 2 & 0 & 0 & 1 & 0 & 7 & 8.0 & NS \\
\hline Rhaphuma diminuta (Bates) & 0 & 0 & 0 & 1 & 0 & 0 & 1 & - & - \\
\hline Xylotrechus cuneipennis (Kraatz) & 2 & 0 & 0 & 0 & 0 & 0 & 2 & - & - \\
\hline \multicolumn{10}{|l|}{ Molorchini } \\
\hline Molorchus minor (L.) & 0 & 0 & 23 & 0 & 2 & 0 & 25 & 24.4 & $<0.01$ \\
\hline \multicolumn{10}{|l|}{ Lamiinae } \\
\hline \multicolumn{10}{|l|}{ Acanthocinini } \\
\hline Leiopus albivittis Kraatz & 1 & 2 & 0 & 0 & 0 & 0 & 3 & 4.0 & NS \\
\hline Leiopus stillatus (Bates) & 0 & 2 & 1 & 0 & 0 & 0 & 3 & 4.0 & NS \\
\hline \multicolumn{10}{|l|}{ Saperdini } \\
\hline Eutetrapha metallescens Motsch. & 0 & 0 & 1 & 0 & 0 & 0 & 1 & - & - \\
\hline \multicolumn{10}{|l|}{ Lepturinae } \\
\hline \multicolumn{10}{|l|}{ Lepturini } \\
\hline Anastrangalia sequensi (Reitter) & 0 & 0 & 0 & 0 & 2 & 0 & 2 & - & - \\
\hline Anoplodera cyanea (Gebler) & 0 & 0 & 0 & 1 & 0 & 1 & 2 & - & - \\
\hline Stictoleptura variicornis (Dalman) & 0 & 0 & 0 & 0 & 1 & 1 & 2 & - & - \\
\hline \multicolumn{10}{|l|}{ Rhagiini } \\
\hline Evodinus borealis (Gyllenhal) & 5 & 0 & 4 & 0 & 0 & 0 & 9 & 16.3 & $<0.01$ \\
\hline Pidonia alticollis (Kraatz) & 1 & 0 & 0 & 1 & 0 & 0 & 2 & - & - \\
\hline Pidonia amurensis Pic & 0 & 0 & 0 & 0 & 1 & 0 & 1 & - & - \\
\hline Rhagium inquisitor rugipenne Reitter & 0 & 1 & 0 & 0 & 0 & 0 & 1 & - & - \\
\hline \multicolumn{10}{|l|}{ Sachalinobiini } \\
\hline Sachalinobia koltzei (Heyden) & 2 & 0 & 0 & 0 & 0 & 0 & 2 & - & - \\
\hline \multicolumn{10}{|l|}{ Necydalinae } \\
\hline \multicolumn{10}{|l|}{ Necydalini } \\
\hline Necydalis pennata Lewis & 1 & 0 & 3 & 0 & 0 & 5 & 9 & 16.5 & $<0.01$ \\
\hline Necydalis sachalinensis Matsumura \& Tamanuki & 0 & 0 & 0 & 0 & 1 & 0 & 1 & - & - \\
\hline \multicolumn{10}{|l|}{ Spondylidinae } \\
\hline \multicolumn{10}{|l|}{ Asemini } \\
\hline Asemum spp. Eschscholtz & 0 & 0 & 1 & 1 & 0 & 0 & 2 & - & - \\
\hline Tetropium castaneum $(\mathrm{L})$. & 2 & 5 & 0 & 1 & 1 & 0 & 9 & 5.0 & NS \\
\hline No. species detected & 10 & 7 & 7 & 7 & 7 & 3 & 22 & $4.6^{1}$ & NS \\
\hline No. specimens captured & 21 & 58 & 37 & 50 & 9 & 7 & 182 & $75.3^{1}$ & $<0.01$ \\
\hline
\end{tabular}

11.8, $P<0.0001$ ) (Fig. 2e) and Evodinus borealis (Gyllenhal) (Lepturinae) $\left(F_{5,35}=4.7, P=0.002\right)$, but for the latter species, E alone was just as effective. Unbaited traps captured significantly more Necydalis (Necydalisca) pennata Lewis (Necydalinae) than did any baited traps $\left(F_{5,35}=4.9\right.$, $P=0.002)$. Each species for which mean catch per trap differed significantly among treatments also differed significantly in the proportion of traps that detected at least one specimen of that species. However, we illustrate only those species for which mean catch is not already shown, i.e., P. testaceus, P. bicuneata, E. borealis, and N. pennata (Fig. 2f-j).

Species composition was generally more similar among lure treatments in 2009 (4-8 shared species and a mean MH index of 0.49) than in 2010 (0-4 shared species and a mean $\mathrm{MH}$ index of 0.17) (Table 3). In 2009, species composition in traps baited with $\mathrm{SB}+\mathrm{E}, \mathrm{F}+\mathrm{SB}+\mathrm{E}$, and $\mathrm{FA}+\mathrm{SB}+\mathrm{E}$ was very similar $(\mathrm{MH}$ index $=0.835-0.995)$, 
a) Tetropium castaneum 2009

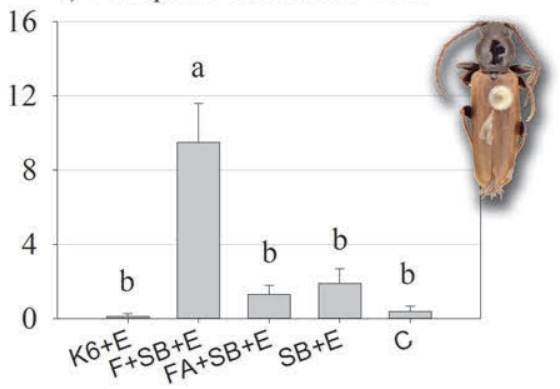

b) Asemum sp. 2009

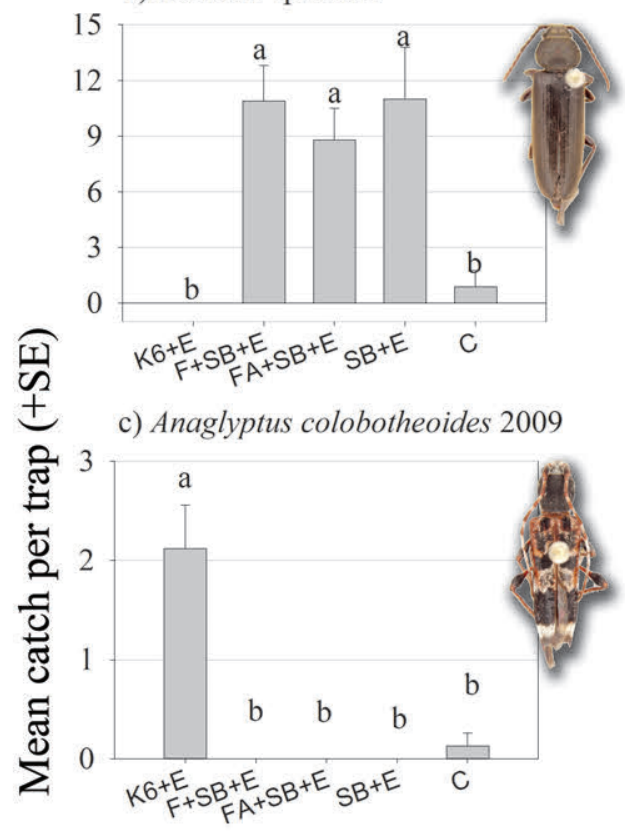

d) Anaglyptus colobotheoides 2010

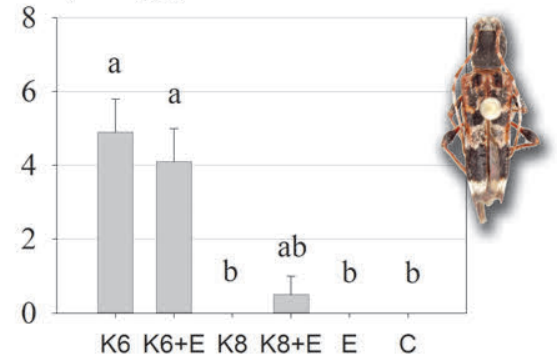

e) Molorchus minor 2010

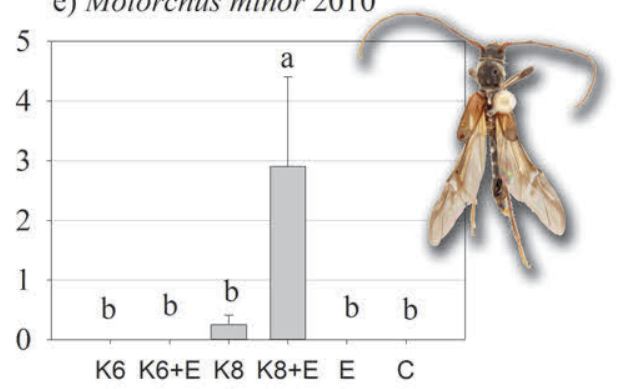

f) Phymatodes testaceus 2009

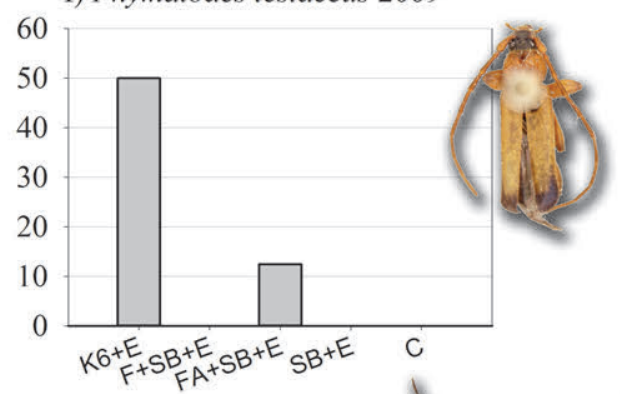

g) Pachyta bicuneata 2009

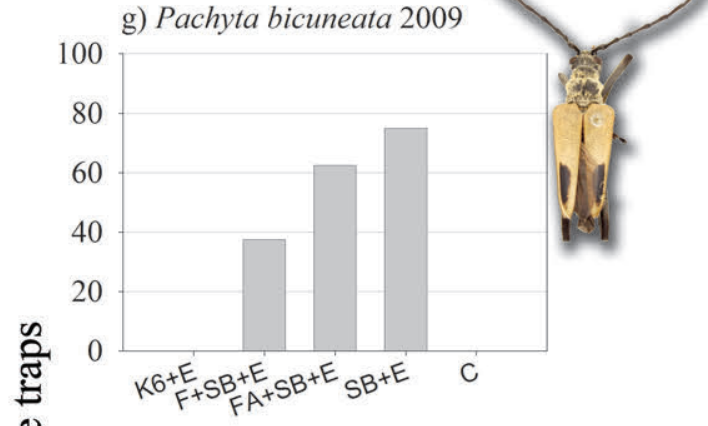

h) Phymatodes testaceus 2010

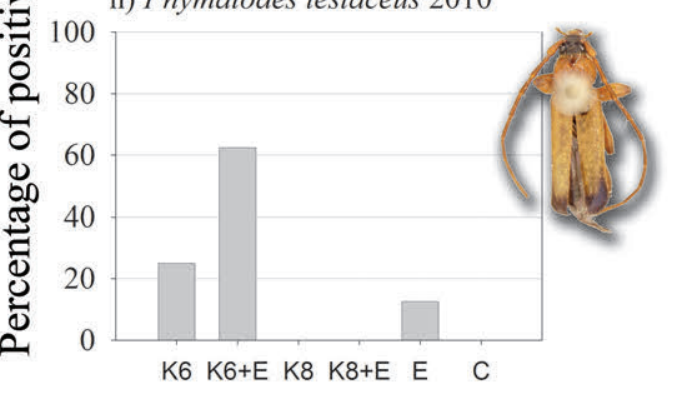

i) Evodinus borealis 2010

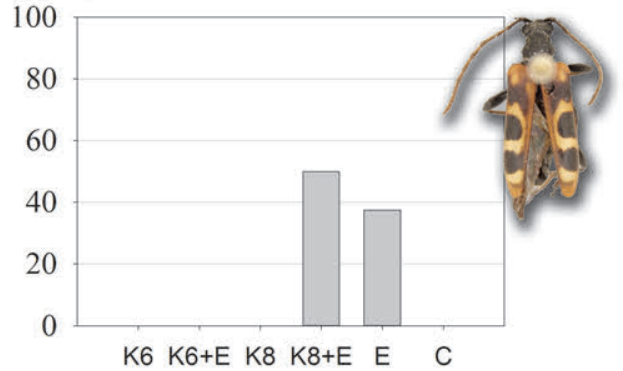

j) Necydalis pennata 2010

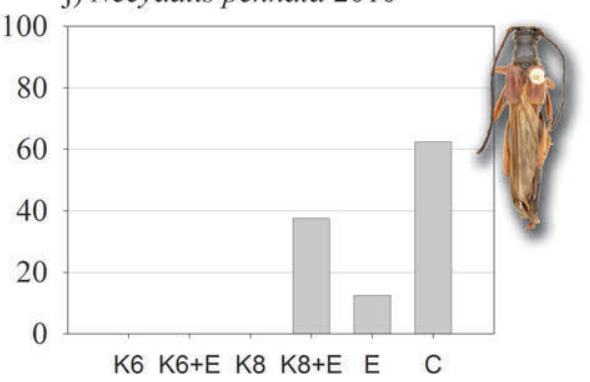

Fig. 2 (a-e). Mean numbers of longhorn species captured in intercept traps baited with various semiochemical lures (K6= racemic 3-hydroxyhexan-2-one; K8 = racemic 3-hydroxyoctan-2-one; $\mathrm{E}$ = ethanol; $\mathrm{SB}=$ spruce blend; $\mathrm{F}=$ racemic fuscumol; and $\mathrm{FA}=$ fuscumol acetate) or left unbaited $(\mathrm{C}=$ control), and $(\mathrm{f}-\mathrm{j})$ percentage of traps that detected at least one specimen of various longhorn beetle species in the Russian Far East in 2009 and 2010. Note: E lures contained 95\% ethanol in 2009 and 40\% ethanol (vodka) in 2010. Means with different letters in Figs 2a-e were significantly different (GLM or Friedmans test on ranks and Ryan-Einot-Gabriel-Welsh multiple range test $(P<0.05)$. 
TABLE 3. Similarity in species composition of longhorn beetles captured in intercept traps baited with different semiochemical lures $(\mathrm{K} 6=$ racemic 3-hydroxyhexan-2-one; $\mathrm{K} 8=$ racemic 3-hydroxyoctan-2-one; $\mathrm{E}=$ ethanol; $\mathrm{SB}=$ spruce blend; $\mathrm{F}=$ racemic fuscumol; FA = fuscumol acetate) or left unbaited, near Vladivostok, Russia, in 2009 and 2010. Note: E lures contained 95\% ethanol in 2009 and 40\% ethanol (vodka) in 2010. For both the Sorenson index and Morasita-Horn index, a greater value indicates greater similarity in species composition. Indices were calculated using EstimateS 9 (Colwell, 2013).

\begin{tabular}{cccccc}
\hline Year & Lure 1 & Lure 2 & $\begin{array}{c}\text { No. sp. } \\
\text { shared }\end{array}$ & Sorenson & $\begin{array}{c}\text { Morasita- } \\
\text { Horn }\end{array}$ \\
\hline & K6+E & SB+E & 4 & 0.320 & 0.013 \\
K6+E & FA+SB+E & 6 & 0.429 & 0.025 \\
K6+E & F+SB+E & 3 & 0.240 & 0.034 \\
K6+E & Unbaited & 7 & 0.538 & 0.201 \\
SB+E & FA+SB+E & 8 & 0.552 & 0.995 \\
SB+E & F+SB+E & 8 & 0.615 & 0.849 \\
SB+E & Unbaited & 7 & 0.519 & 0.643 \\
FA+SB+E & F+SB+E & 8 & 0.552 & 0.835 \\
FA+SB+E & Unbaited & 7 & 0.467 & 0.653 \\
F+SB+E & Unbaited & 6 & 0.444 & 0.656 \\
\hline K6 & K8 & 1 & 0.143 & 0.017 \\
K6 & E & 3 & 0.353 & 0.032 \\
K6 & K6+E & 3 & 0.429 & 0.918 \\
K6 & K8+E & 2 & 0.286 & 0.163 \\
K6 & Unbaited & 1 & 0.200 & 0.005 \\
K8 & E & 2 & 0.235 & 0.244 \\
K8 & K6+E & 2 & 0.286 & 0.049 \\
K8 & K8+E & 1 & 0.143 & 0.477 \\
K8 & Unbaited & 1 & 0.200 & 0.045 \\
E & K6+E & 4 & 0.471 & 0.118 \\
E & K8+E & 2 & 0.235 & 0.105 \\
E & Unbaited & 1 & 0.154 & 0.098 \\
K6+E & Unbaited & 2 & 0.286 & 0.155 \\
K6+E & Unbaited & 0 & 0 & 0 \\
K8+E & Unbaited & 1 & 0.200 & 0.119 \\
\hline & & & & \\
& & & &
\end{tabular}

but much less similar to that in traps baited with $\mathrm{K} 6+\mathrm{E}$ $(\mathrm{MH}$ index $=0.013-0.034)$ (Table 3). For example, 2010 species composition in traps baited with $\mathrm{K} 6$ and $\mathrm{K} 6+\mathrm{E}$ was very similar $(\mathrm{MH}$ index $=0.918)$ but differed greatly from that in traps baited with $\mathrm{K} 8(\mathrm{MH}$ index $=0.017-0.049)$, E $(\mathrm{MH}$ index $=0.032-0.118)$, or $\mathrm{K} 8+\mathrm{E}(\mathrm{MH}$ index $=0.155$ 0.163 ) (Table 3).

Rarefaction curves indicated that, with the exception of traps baited with $\mathrm{K} 6+\mathrm{E}$ and $\mathrm{K} 8+\mathrm{E}$, the mean number of species detected had not reached an asymptote for any lure treatment at our peak sampling intensities of eight trap samples (Fig. 3a, c) or 16 trap samples, when catches from two different lure treatments were combined (Fig. 3b, d). Traps baited with $\mathrm{FA}+\mathrm{SB}+\mathrm{E}$ detected the most species per trapping effort in 2009, and traps baited with $\mathrm{E}$ did so in 2010 (Fig. 3a, c). Unbaited traps detected more species per trapping effort than expected in 2009 but much fewer in 2010, and in most cases, only one individual was captured per species. When catch data were pooled for various binary combinations of lure treatments, we expected the species richness per sampling effort to be greater for those combinations whose lure treatments differed most on species composition. This appeared to be true in some cases, e.g., the combination of catches from traps baited with $\mathrm{SB}+\mathrm{E}$ and $\mathrm{F}+\mathrm{SB}+\mathrm{E}$ detected a maximum of only 18 species compared with 22 captured by the combination of traps baited with $\mathrm{K} 6+\mathrm{E}$ and $\mathrm{F}+\mathrm{SB}+\mathrm{E}$ (Fig. 3b). However, there was little difference in species accumulation curves between the combined catch of $\mathrm{K} 6+\mathrm{E}$ plus $\mathrm{FA}+\mathrm{SB}+\mathrm{E}$, which had dissimilar species compositions, and that of $\mathrm{SB}+\mathrm{E}$ plus $\mathrm{FA}+\mathrm{SB}+\mathrm{E}$, whose species compositions were similar (Fig. 3b).

\section{DISCUSSION}

Our data support the predictions of Hanks et al. (2007) that multiple species in the subfamily Cerambycinae would be attracted to compounds in the 2,3-diol/hydroxyketone motif. We found that racemic hydroxyketones (i.e., K6, K8) increased the efficacy of detecting three of eight species of Cerambycinae: A. colobotheoides, P. testaceus, and $M$. minor. However, detection of the latter two species required an ethanol lure (E) in addition to the ketol lure; only $A$. colobotheoides was significantly attracted to a ketol (K6) lure alone. This is the first report of attraction of $A$. colobotheoides and $M$. minor to hydroxyketones. Hanks \& Millar (2012) observed attraction of $P$. testaceus to racemic 3-hydroxyhexan-2-one in trapping experiments conducted in Pennsylvania.

The combination of F, SB, and $\mathrm{E}$ was attractive to $T$. castaneum, as shown previously by Sweeney et al. (2010). The combination of SB and E was attractive to Asemum spp. as well as a Lepturinae species, $P$. bicuneata, but the addition of F or FA did not enhance trap catch. Specimens of Asemum spp. and T. castaneum accounted for more than $70 \%$ of all longhorned beetle specimens captured in 2009 but for less than $5 \%$ of specimens in 2010; the absence of $\mathrm{F}$ and SB lures in our 2010 experiments likely accounted for the big difference between years in number of specimens captured. Unlike Mitchell et al. (2011), we did not capture significant numbers of Lamiinae species in traps baited with F or FA. It is possible that Lamiinae species present at our site are not attracted to F or FA. However, it is also possible that differences in our methods accounted for the discrepancy between our results and those of Mitchell et al. (2011): (1) we used (E)-F and (E)-FA, whereas they used $(E / Z) \mathrm{F}$ and $(E / \mathrm{Z}) \mathrm{FA}$; (2) our $\mathrm{F}$ and FA release rates were much lower $(<0.8 \mathrm{mg} / \mathrm{d}$ vs. about $3.5 \mathrm{mg} / \mathrm{d})$; (3) we included high release rate lures of SB and $\mathrm{E}$ on all traps baited with F or FA, whereas they did not, and (4) their traps were coated with Fluon $\AA$, and ours were not. Graham et al. (2010) showed that coating intercept traps with Fluon increased catches of some longhorn species more than tenfold.

Traps baited with ultra high release rate ethanol lures (i.e., our E lures in 2009) are commonly used in trapping surveys for exotic bark- and wood-boring beetles in North America, so we were particularly interested in testing their efficacy in detecting longhorned beetles present at the Russian Far East site. Traps baited with E alone detected the 
a) 2009

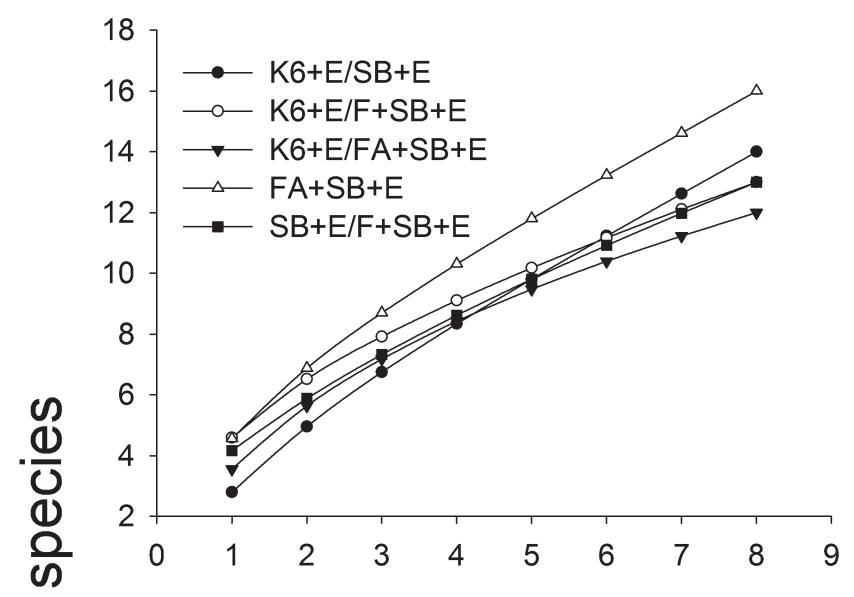

b) 2009 trap lure combinations

i

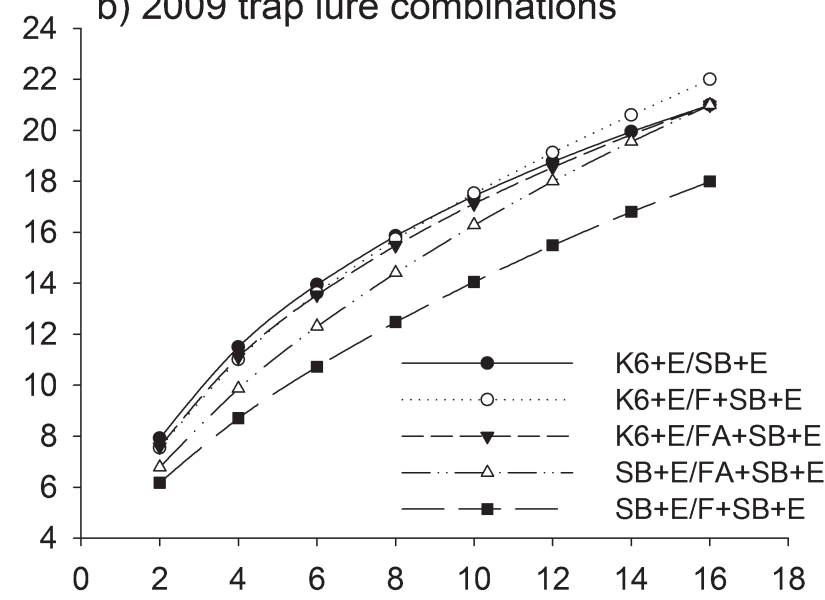

c) 2010

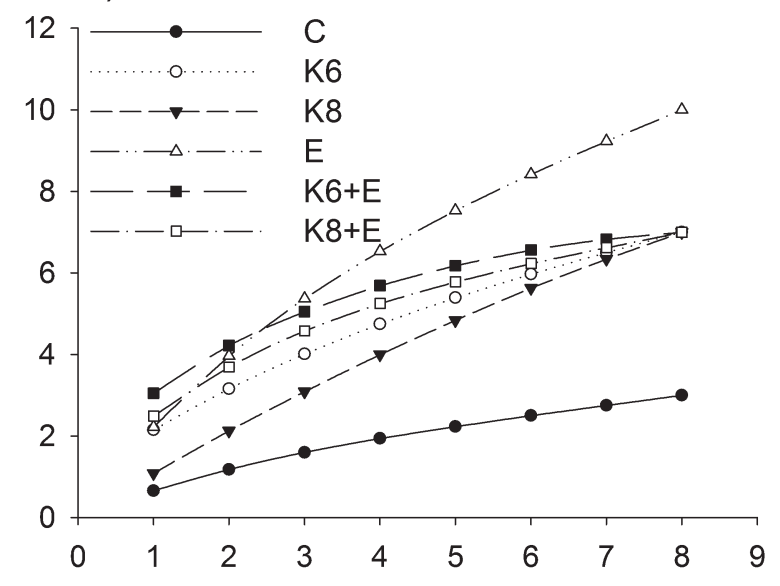

d) 2010 trap lure combinations

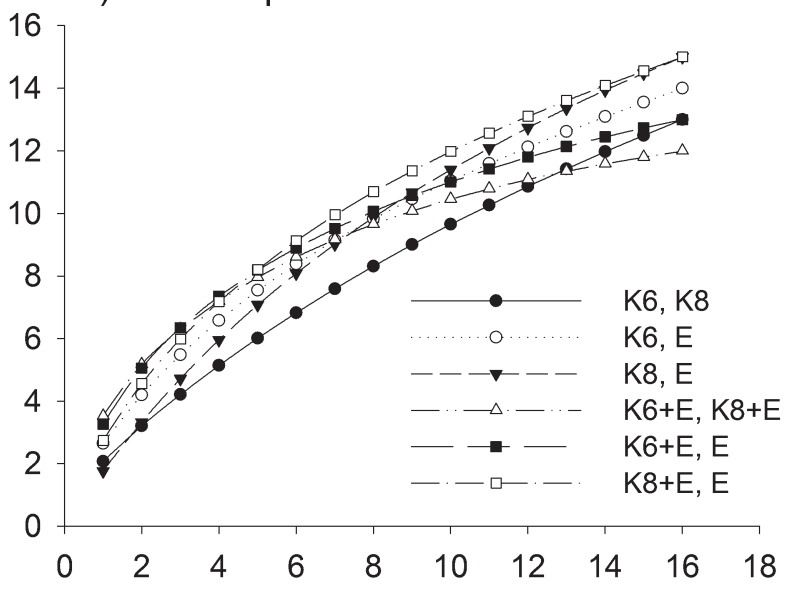

\section{No. of trap samples}

Fig. 3. Mean number of longhorn species detected per number of trap samples, estimated using Coleman's rarefaction, in the Russian Far East in 2009 (a, b) and 2010 (c, d). C = unbaited control; K6 = racemic 3-hydroxyhexan-2-one; K8 = racemic 3-hydroxyoctan2-one; $\mathrm{E}$ = ethanol; $\mathrm{SB}=$ spruce blend; $\mathrm{F}=$ racemic fuscumol; and FA = fuscumol acetate. Note: E lures contained $95 \%$ ethanol in 2009 and $40 \%$ ethanol (vodka) in 2010.

most longhorned species (10) of any lure treatment in 2010 but failed to detect more than half of the total number of longhorned species detected at the site (22). Moreover, traps baited with E alone significantly affected detection rate of only one species, E. borealis. In 2010, the E lures contained vodka ( $40 \%$ ethanol) rather than $95 \%$ ethanol, so release rates would have been about half; thus it is possible that our results may have differed had we used standard ultra high release rate ethanol lures.

Unbaited traps outperformed lure treatments in the detection of $N$. pennata in 2010, suggesting that this species may avoid traps baited with K6, K8, or E. However, evidence for this is weak because a similar trend was not observed in 2009, when traps baited with K6+E captured more $N$. pennata than unbaited traps.

The efficacy and efficiency of trapping surveys for detection of potentially invasive, exotic longhorn species should be increased by lures that increase the diversity of species captured per trap. It is clear from the rarefaction curves that eight traps per site were insufficient to detect all of the longhorn species potentially attracted by any individual lure treatment, i.e., the species accumulation curves failed to reach an asymptote in most cases. We had expected that the combined catches of traps baited with different lures that each attracted a dissimilar set of longhorn species would result in a greater number of species detected per trapping effort. However, this did not appear to be the case. In 2009, traps baited with FA+SB+E detected 16 longhorn species in eight traps (two new species per trap). Combining the catches of traps baited with $\mathrm{FA}+\mathrm{SB}+\mathrm{E}$ with traps baited with $\mathrm{K} 6+\mathrm{E}$ (which detected a dissimilar set of species) resulted in about the same rate of species detection (15.5 per 8 traps, Fig. 3b). Results were similar in 2010, e.g., combined catches of traps baited with K6 and those baited with $\mathrm{K} 8$ detected eight species in eight traps compared with seven species detected in eight traps baited with either lure alone. These results are likely due to the fact that the lure treatments were significantly attractive to relatively few of the longhorn species present, so that for many species, trap capture was more of a random event; 
thus probability of capture was associated more with the number of traps present than the type of lure.

Our results indicate that use of longhorn beetle pheromone lures in trapping surveys will increase the mean catch and probability of detecting certain species of Cerambycidae, including those that may be exotic and potentially invasive. Further work is required to determine the most effective way to incorporate these with the standard lures currently used for early detection of invasive bark- and wood-boring species. A logical next step is to determine whether the addition of longhorn beetle pheromones to traps baited with host volatiles has negative or positive effects on potentially invasive species of Curculionidae that are also targeted in invasive surveillance programs. Noseworthy et al. (2012) found that the combination of racemic 3-hydroxyoctan-2-one and ethanol significantly increased captures of Monarthrum scutellare (LeConte) (Coleoptera: Curculionidae) in Lindgren funnel traps. It is conceivable that some lure combinations may decrease trap catches of other Curculionidae species. Data on catch of Scolytinae (Curculionidae) trapped in the same experiments will be reported separately.

ACKNOWLEDGEMENTS. We thank Natural Resources Canada, Canadian Forest Service Forest Invasives Alien Species program and A. Hopkin (Sault Ste. Marie, ON), the Canadian Food Inspection Agency and T. Kimoto (Vancouver, BC), and the USDA Animal Plant Health Inspection Service and V. Mastro (Buzzards Bay, MA) for support and funding. A.S. Lelej and S.R. Shestakov (Vladivostok, Russia) assisted with the fieldwork logistics. M.E. Smirnov (Ivanovo, Russia) helped to identify specimens. C. Hughes and J. Price (Fredericton, NB, Canada) and T. Kimoto and E. Kovacs (Vancouver, BC, Canada) provided technical and logistical support. B. Gill (Ottawa, ON, Canada), L. Humble (Victoria, BC, Canada), C.M. Simpson (Fredericton, NB, Canada) and two anonymous reviewers reviewed earlier versions of this manuscript.

\section{REFERENCES}

Allison J.D., Borden J.H. \& Seybold S.J. 2004: A review of the chemical ecology of the Cerambycidae (Coleoptera). - Chemoecology 14: 123-150.

Cappaert D., McCullough D.G., Poland T.M. \& Siegert N.W. 2005: Emerald ash borer in North America: A research and regulatory challenge. - Am. Entomol. 51: 152-165.

Cervantes D.E., Hanks L.M., Lacey E.S. \& Barbour J.D. 2006 First documentation of a volatile sex pheromone in a longhorned beetle (Coleoptera: Cerambycidae) of the primitive subfamily Prioninae. - Ann. Entomol. Soc. Am. 99: 718-722.

Colwell R.K. 2013: EstimateS: Statistical Estimation of Species Richness and Shared Species from Samples. Version 9. User's Guide and Application. Available at: http://purl.oclc.org/estimates (accessed January 2014).

FAO IPPC 2013: Regulation of Wood Packaging Material in International Trade. International Standards for Phytosanitary Measures 15. International Plant Protection Convention of the Food and Agricultural Organization. Available at: https://www. ippc.int/publications/regulation-wood-packaging-materialinternational-trade- 0

Fettköther R., Dettner K., Schröder F., Meyer H., Francke W. \& NoldT U. 1995: The male pheromone of the old house borer
Hylotrupes bajulus (L.) (Coleoptera: Cerambycidae): identification and female response. - Experientia 51: 270-277.

FonseCa M.G., Vidal D.M. \& Zarbin P.H.G. 2010: Male-produced sex pheromone of the cerambycid beetle Hedypathes betulinus: chemical identification and biological activity. $-J$. Chem. Ecol. 36: 1132-1139.

Graham E.E., Mitchell R.F., Reagel P.F., Barbour J.D., MilLAR J.G. \& HANKS L.M. 2010: Treating panel traps with a fluoropolymer enhances their efficiency in capturing cerambycid beetles. - J. Econ. Entomol. 143: 643-647.

HanKs L.M. \& Millar J.G. 2012: Field bioassays of cerambycid pheromones reveal widespread parsimony of pheromone structures, enhancement by host plant volatiles, and antagonism by components from heterospecifics. - Chemoecology 23: 21-34.

Hanks L.M., Millar J.G., Mongold-Diers J.A., Wong J.C.H., Meier L.R., Reagel P.F. \& Mitchell R.F. 2012: Using blends of cerambycid beetle pheromones and host plant volatiles to simultaneously attract a diversity of cerambycid species. - Can. J. For. Res. 42: 1050-1059.

Hanks L.M., Millar J.G., Moreira J.A., Barbour J.D., Lacey E.S., McElfresh J.S., Reuter F.R. \& Ray A.M. 2007: Using generic pheromone lures to expedite identification of aggregation pheromones for the cerambycid beetles Xylotrechus nauticus, Phymatodes lecontei, and Neoclytus modestus modestus. — J. Chem. Ecol. 33: 889-907.

Kimmerer T.W. \& Kozlowski T.T. 1982: Ethylene, ethane, acetaldehyde, and ethanol production by plants under stress. Plant Physiol. 69: 840-847.

Kovacs K.F., Haight R.G., McCullough D.G., Mercader R.J., Siegert N.W. \& LiebHold A.M. 2010: Cost of potential emerald ash borer damage in U.S. communities, 2009-2019. Ecol. Econom. 69: 569-578.

Krestov P.V. 2003: Chapter 5. Forest vegetation of easternmost Russia (Russian Far East). In Kolbek J., Šrůtek M. \& Box E.O. (eds): Forest Vegetation of Northeast Asia. Kluwer Academic Publishers, Dordrecht, pp. 93-180.

Lacey E.S., Ginzel M.D., Millar J.G. \& Hanks L.M. 2004: Male-produced aggregation pheromone of the cerambycid beetle Neoclytus acuminatus acuminatus. - J. Chem. Ecol. 30: 1493-1507.

Lacey E.S., Moreira J.A., Millar J.G., Ray A.M. \& Hanks L.M., 2007: Male-produced aggregation pheromone of the longhorned beetle Neoclytus mucronatus mucronatus. - Entomol. Exp. Appl. 122: 171-179.

Leal W.S., Shi X., Nakamuta K., Ono M. \& Meinwald J. 1995: Structure, stereochemistry, and thermal isomerization of the male sex pheromone of the longhorn beetle Anaglyptus subfasciatus. - Proc. Nat. Acad. Sci. USA 92: 1038-1042.

Löbl I. \& Smetana A. (eds) 2010: Catalog of Palearctic Coleoptera. Vol. 6. Apollo Books, Stenstrup, 924 pp.

Millar J.G., Hanks L.M., Moreira J.A., Barbour J.D. \& Lacey E.S. 2009: Pheromone chemistry of cerambycid beetles. In Nakamuta K. \& Millar J.G. (eds): Chemical Ecology of Woodboring Insects. Forestry and Forest Products Research Institute, Ibaraki, pp. 52-79.

Mitchell R.F., Graham E.E., Wong J.C.H., Reagel P.F., Striman B.L., Hughes G.P., Paschen M.A., Ginzel M.D., Millar J.G. \& HanKs L.M. 2011: Fuscumol and fuscumol acetate are general attractants for many species of Cerambycid beetles in the subfamily Lamiinae. - Entomol. Exp. Appl. 141: 71-77.

Nehme M.E., Keena M.A., Zhang A., BaKer T.C. \& Hoover K. 2009: Attraction of Anoplophora glabripennis to male-produced pheromone and plant volatiles. - Environ. Entomol. 38: 1745-1755. 
Noseworthy M.K., Humble L.M., Sweeney J., Silk P.J. \& Mayo P. 2012: Attraction of Monarthrum scutellare (Coleoptera: Curculionidae: Scolytinae) to hydroxy ketones and host volatiles. - Can. J. For. Res. 42: 1851-1857.

Nowak D.J., Pasek J.E., Sequeira R.A., Crane D.E. \& Mastro V.C. 2001: Potential effect of Anoplophora glabripennis (Coleoptera: Cerambycidae) on urban trees in the United States. - J. Econ. Entomol. 94: 116-122.

Pajares J.A., Álvarez G., Ibeas F., Gallego D., Hall D.R. \& FARMAN D.I. 2010: Identification and field activity of a maleproduced aggregation pheromone in the pine sawyer beetle, Monochamus galloprovincialis. - J. Chem. Ecol. 36: 570 583.

Poland T.M. \& McCullough D.G. 2006: Emerald ash borer: invasion of the urban forest and the threat to North America's ash resource. - J. For. 104: 118-124.

Ray A.M., Lacey E.S. \& Hanks L.M. 2006: Predicted taxonomic patterns in pheromone production by longhorned beetles. Naturwissenschaften 93: 543-550.

Ray A.M., Žunič A., Alten R.L., McElfresh J.S., Hanks L.M. \& Millar J.G. 2011: cis-Vaccenyl acetate, a female-produced sex pheromone component of Ortholeptura valida, a longhorned beetle in the subfamily Lepturinae. - J. Chem. Ecol. 37: $173-178$

Roelofs W.L. \& CARDÉ R.T. 1977: Responses of Lepidoptera to synthetic sex pheromone chemicals and their analogues. Annu. Rev. Entomol. 22: 377-405.

SAS Institute 2002-2003: Proprietary Software Release 9.1. SAS Institute Inc., Cary, NC, USA.

Silk P.J., Sweeney J., Wu J., Price J., Gutowski J.M. \& Kettela E. 2007: Evidence for a male produced pheromone in Tetropium fuscum (F.) and Tetropium cinnamopterum (Kirby) (Coleoptera: Cerambycidae). — Naturwissenschaften 94: 697-701.

Sweeney J.D., de Groot P., Macdonald L., Smith S., Cocquempot C., Kenis M. \& Gutowski J.M. 2004: Host volatile attractants for detection of Tetropium fuscum (F.), Tetropium castaneum (L.), and other longhorned beetles (Coleoptera: Cerambycidae). - Environ. Entomol. 33: 844-854.

Sweeney J.D., Gutowski J.M., Price J. \& de Groot P. 2006: Effect of semiochemical release rate, killing agent, and trap design on detection of Tetropium fuscum (F.) and other longhorn beetles (Coleoptera: Cerambycidae). - Environ. Entomol. 35: 645-654.

Sweeney J.D., Silk P.J., Gutowski J.M., Wu J., Lemay M.A., Mayo P.D. \& MAgee D.I. 2010: Effect of chirality, release rate, and host volatiles on response of Tetropium fuscum (F.), Tetropium cinnamopterum (Kirby), and Tetropium castaneum (L.) (Coleoptera: Cerambycidae) to the aggregation pheromone, fuscumol. - J. Chem. Ecol. 36: 1309-1321.

Teale S.A., Wickham J.D., Zhang F., Su J., Chen Y., Xiao W., Hanks L.M. \& Millar J.G. 2011: A male-produced aggregation pheromone of Monochamus alternatus (Coleoptera: Cerambycidae), a major vector of pine wood nematode. $-J$. Econ. Entomol. 104: 1592-1598.

Tilles D.A., SJodin K., Nordlander G. \& Eidmann H.H. 1986: Synergism between ethanol and conifer host volatiles as attractants for the pine weevil, Hylobius abietis (Coleoptera: Curculionidae). - J. Econ. Entomol. 79: 970-973.

Wong J.C.H., Mitchell R.F., Striman B., Millar J.G. \& Hanks L.M. 2012: Blending synthetic pheromones of Cerambycid beetles to develop trap lures that simultaneously attract multiple species. - J. Econ. Entomol. 105: 906-915.

ZAR J.H. 1999: Biostatistical Analysis. 4th ed. Prentice-Hall, Upper Saddle River, NJ, 663 pp.

Zhang A., Oliver J.E., Aldrich J.R., Wang G.B. \& Mastro V.C. 2002: Stimulatory beetle volatiles for the Asian longhorned beetle, Anoplophora glabripennis (Motschulsky). - Z. Naturforsch. (C) J. Biosci. 57: 553-558.

Received March 4, 2014; revised and accepted April 25, 2014 Prepublished online May 27, 2014 